\section{Application of thermographic analysis for the detection of longitudinal defects in cold mills*}

\author{
J.A. González, F. Obeso (Aceralia Steel Corp.), \\ D.F. García, R. Usamentiaga (University of \\ Oviedo), R. Falessi (CSM)
}

The paper will present the work done to assess the usefulness of the thermographic analysis in the design of a detection system for longitudinal defects in coils manufactured by a tandem cold mill. The approach started with a first phase devoted to the development of a computer system for the acquisition of high resolution thermal maps of the whole strip. In the second phase the thermal maps are classified and related to the process variables.

\section{INTRODUCTION}

The pressing demand to improve the quality in the steel rolling industry requires the use of the latest technology or to explore new ones, in order to detect and avoid product defects $(1,2)$, and in this way, to make a better adjustment of the manufacturing parameters, producing better products.

The work presented in this paper uses the latest hardware technology in infrared sensors to acquire the temperature of a tin plate strip during its rolling at a high frequency. The thermographic sensor uses a scanning system that allows the temperature measurement in several points of the strip, that is, scan acquisition, instead of spot acquisition. This sensor capability joined to the fast acquisition frequency, allows the temperature measurement of the entire strip while it is being rolled in the cold mill. Finally, a thermographic image of the strip is obtained by combining all the scans captured using the information about the speed of the strip while it was rolled.

The goals of the work are to show the relationship between temperature and flatness, and the detection of longitudinal defects using the thermographic information obtained through the sensor (3).

Longitudinal defects are mainly related to flatness problems produced by miscellaneous factors in the processing of the cold mill, like refrigeration, or rolling strength. If the defects are detected while the strip is being processed, the rolling parameters can be modified in order to solve the problem and improve the quality of the final product.

\section{THERMOGRAPHY ACQUISTION}

\section{Description of the system}

The system is composed of four elements, shown in figure 1 , whose description and functionality is briefly presented below.

- An infrared sensor, specially developed by LAND Company for this application $(4,5)$, scans the temperature across the strip 80 times per second. During each scan, the sensor generates an analog signal proportional to the temperature of the strip.
* Subject of a presentation at the 2001 ATS International Steelmaking Conference (Paris, December 12-13, 2001, Session 7).

The authors would like to thank the European Commission, which has funded the project under the research contract 7210-PR-149 of the ECSC (European Coal and Steel Community) Program.

(C) La Revue de Métallurgie 2002. 


\section{Utilisation de la thermographie pour la détection des défauts longitudinaux au laminoir à froid}

\author{
A. González, F. Obeso (Aceralia Steel Corp.), \\ D.F. García, R. Usamentiaga (University of \\ Oviedo), R. Falessi (CSM)
}

La maîtrise de la qualité dans le laminage de l'acier nécessite le recours à des techniques performantes de détection de défauts, qu'elles existent ou qu'il faille en trouver de nouvelles. Dans cet article on examine les possibilités qu'offre l'emploi de la thermographie infrarouge sur un laminoir à fer-blanc. La carte de température de la bande en défilement renseigne sur la planéité de la tôle et sur la présence de défauts longitudinaux.

\section{Acquisition des données thermographiques}

Le système qui a été installé à ACERALIA est composé de quatre élements :

- un capteur infrarouge, mis au point spécialement par la société LAND pour cette application ;

- un PC industriel équipé d'une carte d'acquisition rapide $P C I-M O I-16 E$;

- une liaison avec le calculateur de process qui fournit les paramètres de fabrication nécessaires à l'analyse des images thermographiques;

- des PC de visualisation qui permettent de voir les cartes de température et d'accéder aux paramètres de fabrication.

Le système est conçu avec une organisation à trois niveaux, avec un nombre minimal d'éléments à chaque niveau. Le capteur infrarouge est relié à une instrumentation permettant d'introduire dans le système des paramètres de fabrication comme la vitesse de la bande, et de fournir des signaux de sortie comme des alarmes pour les automates programmables. Les images obtenues permettent aux opérateurs de laminage de suivre la température de la bande et aux contrôleurs de la qualité d'analyser les défauts détectés par le système.

Avant utilisation, un double étalonnage est nécessaire : celui de la mesure de température et celui de la distance. Pour l'étalonnage de la température, la mesure fournie par le capteur infrarouge est comparée à celle mesurée en axe de bande par un pyromètre. En réglant le facteur d'émissivité utilisé pour convertir le signal du capteur infrarouge en température, on fait coïncider ces deux mesures. Pour l'étalonnage de la distance entre le capteur et le point visé sur la bande, on place des résistances chaudes en différentes positions dans la largeur de la bande et on établit une corrélation entre le signal obtenu et la distance à chaque zone chauffée.
Les données fournies par le système peuvent être visualisées dans la cabine de commande du laminoir ou à distance. Trois formes de réprésentation sont possibles : une carte de température à deux dimensions, un balayage linéaire, une indication de type pyromètre. En combinant ces informations, les responsables de la qualité peuvent évaluer l'influence de la température ou d'autres paramètres sur la planéité de la bande et décider de mesures correctives éventuelles.

\section{Traitement des données thermographiques}

Après acquisition des données, un traitement est nécessaire pour éliminer le bruit superposé au signal. Ce traitement est réalisé au moyen d'un filtre qui travaille successivement dans la direction transversale et la direction longitudinale. Pour cela on compare les données relatives à des points défférents d'une même ligne de balayage et de différentes lignes de balayage. Une ligne de balayage transversale donnée est analysée avec différents schémas d'échantillonnage, ce qui produit un chevauchement des données correspondantes. Ceci permet de lisser ces données. Dans le sens longitudinal, le signal est lissé par une procédure d'aggrégation des valeurs ponctuelles. Le filtrage est fait dans des conditions telles que des variations rapides de température restent nettement détectables.

\section{Interprétation des données}

Sur l'image thermographique traitée, des différences de température le long de la bande sont mises en évidence. Ces différences sont à l'origine de défauts de planéité après refroidissement. Les cartes de planéité obtenues sous forte tension et à température homogène ne révèlent pas de gros défauts de planéité (on se situe à \pm 5 U.I.). Les défauts se développent après refroidissement de la bande du fait de l'hétérogénéité éventuelle de la contraction du métal entre axe et rives. On peut en prévoir la formation en combinant la carte thermique et la carte de planéité de la bande pendant le laminage. La carte de planéité à froid ainsi calculée est conforme aux observations faites après laminage par le contrôle de production.

La technique utilisée fournit ainsi des indications plus justes que le tensiomètre classique monté sur le laminoir. Alors que pour ce dernier la bande possède une planéité satisfaisante, la carte de planéité à froid calculée à partir des données thermographiques révèle des défauts potentiels avant même que la bande ne soit refroidie. 
- An industrial PC, using a PCIMIO-16E acquisition card (6) samples the analog temperature signal and stores the samples of each scan in memory. Meanwhile, it also represents the infrared map of the strip on a screen installed in the control room of the tandem mill. Finally, when the manufacturing of the strip finishes, it stores the image on the hard disk.

- The process computer sends the manufacturing variables that are essential to interpret the infrared image properly, to the industrial PC.

- The visualization PCs allow the retrieval of the thermal images and manufacturing variables stored in the industrial PC to visualize them.

The architecture of this system is organized in three layers $(7,8)$, with a minimum number of elements in each of the layers, following the low cost approach used for the design of the system.

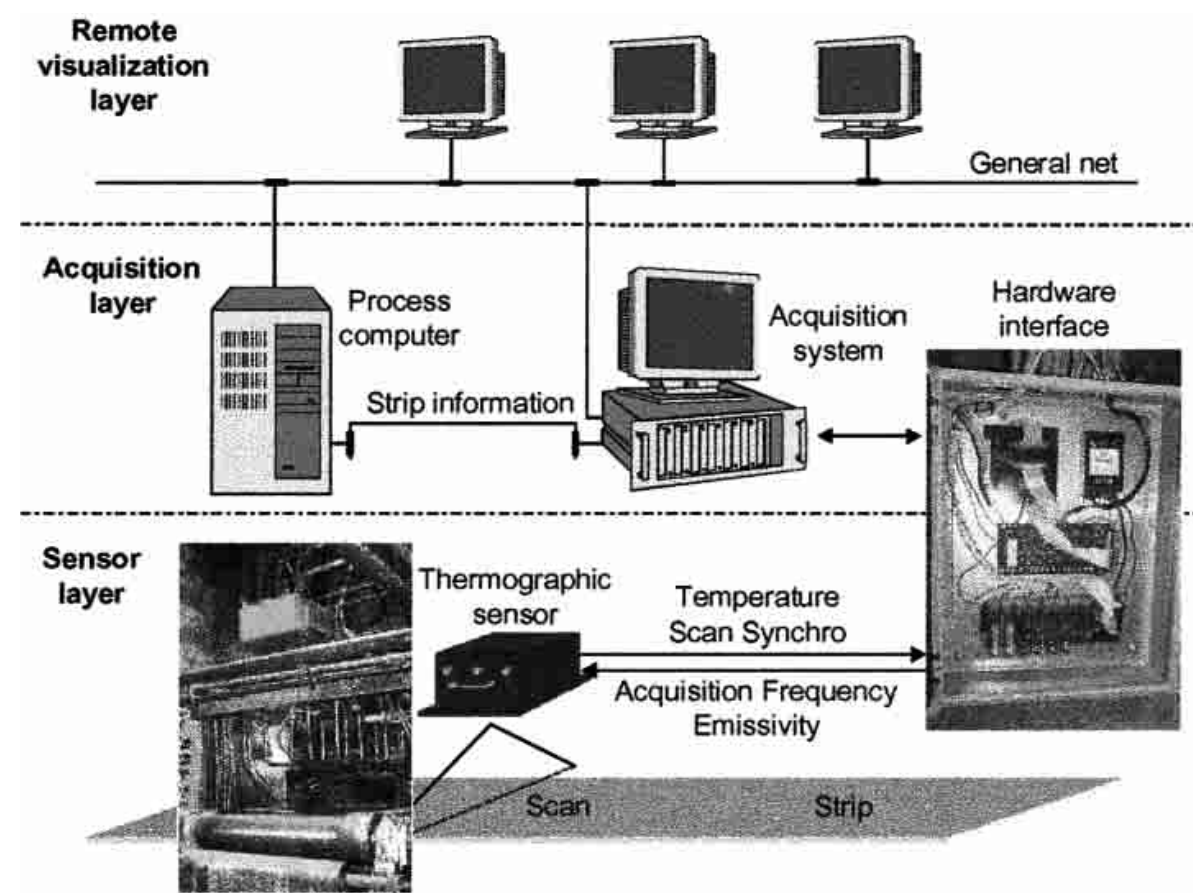

Fig. 1 - Global layout and components of the system.

Fig. 1 - Schéma général et éléments constitutifs du système.
In the acquisition process, the typical infrared thermographic systems usually include capabilities for connecting instrumentation, for input purposes such as acquiring the speed of manufactured material and for output purposes, commonly to send alarms to programmable logic controllers. In this architecture, all the input/output information is handled by the process computer to minimize the cost of the system at the expense of a lower interchange rate.

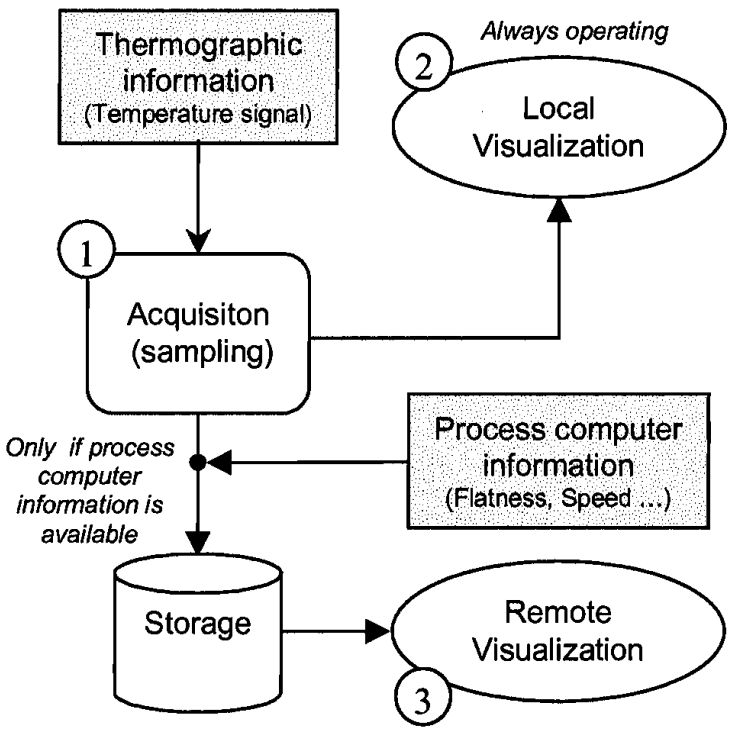

Fig. 2 - Global layout of the system.

Fig. 2 - Organigramme fonctionnel du système.
The design of the system reflects its two main goals :

- show the temperature of the strip to the control operators during its rolling ;

- provide the quality control team with the appropriate information to find the cause of defects detected in the strips.

The comprehension of the operation of the system is easy using the information flow diagram of figure 2 , in which the thermographic information follows three clear steps : (1) acquisition, (2) visualization, and (3) storage.

\section{Calibration}

The system must be calibrated before its start-up. Therefore, procedures for the calibration of two scales, temperatures and distances have been developed.

The calibration of the temperature scale is accomplished by the interactive comparison of the temperatures measured along the centre of the strip by this system and by other calibrated pyrometers. The temperature provided by the infrared sensor is related to the temperature of the material through the black body radiation formula, in which the emissivity of the material is a proportionality factor. Emissivity settings in the range 0.2-1.0 are supplied to the sensor as one of its remote control input signals. The operator decreases the emissivity, to increase the temperature provided by the sensor, and vice versa, until the system provides the same average temperature as the calibrated pyrometer. 
The calibration of the distances is devoted to associate each temperature sample within a scan with its distance to the axis of the mill, D. Equation [1] gives the theoretical distance D in function of the focal distance of the sensor, F, the angle between the sensor axis and the sampled point, q, and the angle between the sensor axis and the mill axis, $\theta_{\mathrm{e}}$.

$$
D=F \cdot \tan \left(\theta-\frac{\pi}{6}\right)-F \cdot \tan \left(\theta_{e}-\frac{\pi}{6}\right)
$$

The angle $\theta$, with which each point is sampled, is given by equation [2]. It depends on the serial number of the sample, $S$, in relation with the total number of samples within the scans, N.

$$
\theta=\left(\frac{S}{N}\right) \frac{\pi}{3}
$$

To determine the angle $\theta_{\mathrm{e}}$ and the parameter $\mathrm{F}$, a hot resistance is successively placed crossing the line scan at distances of $+60,+30,0,-30$, and $-60 \mathrm{~mm}$ from the axis of the mill. After repeating this measurement experiment several times, the system has enough pairs (sample-distance) to obtain the value of $F$ that minimizes the sum of errors between the distances measured and the distances calculated with equations (1) and (2).

Visualization is an important goal of the system. Two kinds of visualization, local and remote (as can be seen in figure 1), can be carried out. The local visualization is shown in the pulpit of the mill, while the remote visualization can be shown in any place of the factory. The local tool allows the visualization of the current rolled strip and the configuration of the system, like the emissivity parameter. The remote visualization is integrated in a tool that allows the analysis of the thermography as well as the variables provided by the process computer.

Both kinds of visualization can show the termographic information in several display types : 2D map, linear scan, and virtual pyrometer. Combining the three types of displays, the quality control engineers can evaluate the influence of temperature and other variables on the final flatness of the rolled strips, and apply the proper compensations to reach an acceptable flatness in the manufactured strips.

\section{- THERMOGRAPHY ENHANCEMENT}

The first step after the acquisition is the enhancement. The thermographic enhancement tries to eliminate the noise of the signal to reach a successful analysis.
The temperature measurement using non-contact sensors at high frequencies produces a very noisy signal. The noise is mainly caused by the standing products over the strip used to refrigerate it, which alter the surface properties of the steel, and provoke erroneous measurements.

The designed filter to eliminate the noise, works in two sequential steps : transversal, and longitudinal. The use of these two steps is based on the analysis of the differences between spots in the same scan, and spots in different scans.

The filter in the transversal direction consists of an oversampling, using the highest acquisition frequency available in the system. The process is shown in figure 3.

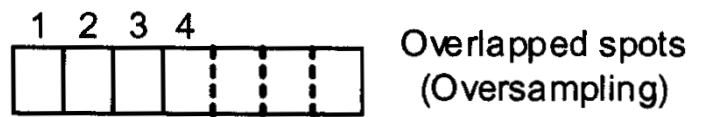

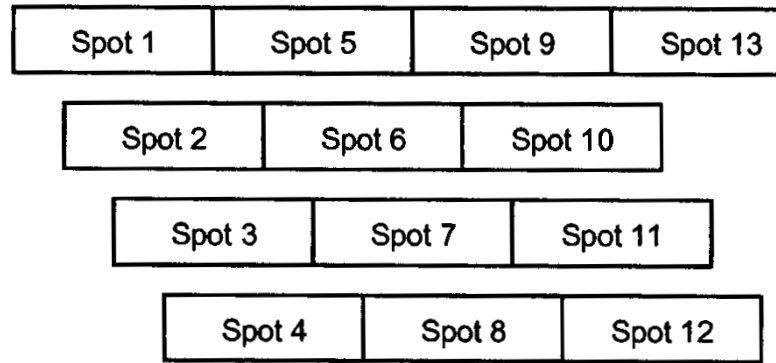

Fig. 3 - Oversampling process.

Fig. 3 - Procédure d'échantillonnage redondant.

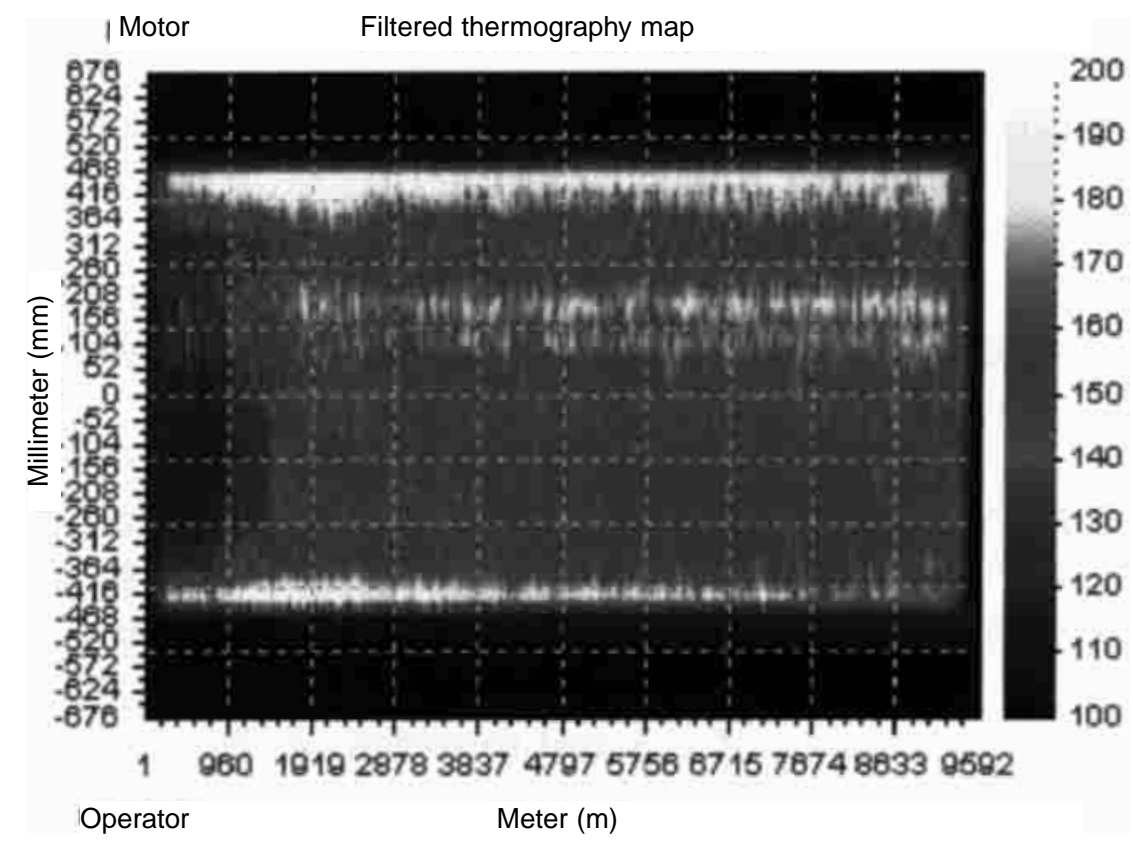

Fig. 4 - Thermograhic image of coil 585 after filtering in both directions.

Fig. 4 - Image thermographique de la bobine $n^{\circ} 585$ après filtrage du signal dans les deux directions. 
Figure 3 shows the oversampling process, in which several overlapped spots are captured. Once the scan is captured, the data are reduced to the minimum number of spots that fill the scan space without overlapping. The formula to obtain a new intermediate spot will be :

$$
\begin{aligned}
\mathrm{N}_{\mathrm{i}}= & \mathrm{S}_{\mathrm{i}} * 0.0625+\mathrm{S}_{\mathrm{i}+1} * 0.125+\mathrm{S}_{\mathrm{i}+2} * 0.1875+\mathrm{S}_{\mathrm{i}+3} * 0.25 \\
& +\mathrm{S}_{\mathrm{i}+4} * 0.1875+\mathrm{S}_{\mathrm{i}+5} * 0.125+\mathrm{S}_{\mathrm{i}+6} * 0.0625
\end{aligned}
$$

where $\mathrm{N}$ corresponds to a new spot, and $\mathrm{S}$ to adjacent captured spots.

In the longitudinal direction the filteriing is carried out by making a spot aggregation. The selected criteria in the data aggregation involved the analysis of all strips obtained during the capture campaign, in order to find the fastest change of speed. The aggregation selected smoothes the signal and allows the fast temperature changes to remain clearly visible.

The goal of the filter is to eliminate the noise and to smooth the signal, but following the aggregation criteria, the space needed to store the data in memory and in disk later, is hardly decreased. The space needed to store the reduced data is about $75 \%$ of the space occuped by the raw data.

Figure 4 shows the thermographic map of a strip after being filtered. Temperature differences can be observed from the edges to the centre of the strip. This problem will be translated into flatness defects.

Figure 4 has been directly extracted from the remote visualization software developed for this system, which allows the visualization and the analysis of the captured images. The grey level bar on the right, shows the temperature scale in degrees centigrade.

\section{- THERMOGRAPHY ANALYSIS}

\section{Flatness maps}

After analysis of the information of the strips obtained during the capture campaign, temperature differences appear along the material.

However, the flatness map generated by the stressometer (flatness meter) for most of these strips is good enough, showing all the strip flatness indices within the range of \pm 5 I-units.

Figure 5 shows the flatness map of the coil of the previous figure, showing the thermographic map. The bar on the right shows the I-units scale multiplied by 100 . This flatness map is obtained with the strip under strong tension, without non-uniformities. According to the information of this map, the rolled strip should be classified as an optimal rolled strip.

After complete cooling, when the strip is further processed in other facilities, as continuous annealing lines, flatness defects appear newly.

The flatness measurement is obtained when the strip is under tension and hot. When the strip looses the tension and gets cold, the flatness obviously changes.

During the cooling of any hot material, a physical effect known as contraction is produced. This consists of the reduction of the dimensions of the material. The contraction is the reaction to the dilatation action (action-reaction). The reduction of the material (contraction) is directly proportional to the temperature of the material, using as parameter the properties of the material.

In the coil shown in the figures 4 and 5, the contraction provokes a faulty strip, due to flatness problems. After cooling, the edges become very stretched, while the centre of the strip is quite loose.

This shows that the lack of uniformity in the temperatures across the strip generates flatness defects, when the strip contracts itself during cooling.

These flatness problems make further processing very difficult and slower, that is, the production rate is decreased. The flatness problems were not detected through the flatness measurement, but they could have been detected using both the information about flatness and the information about temperature.

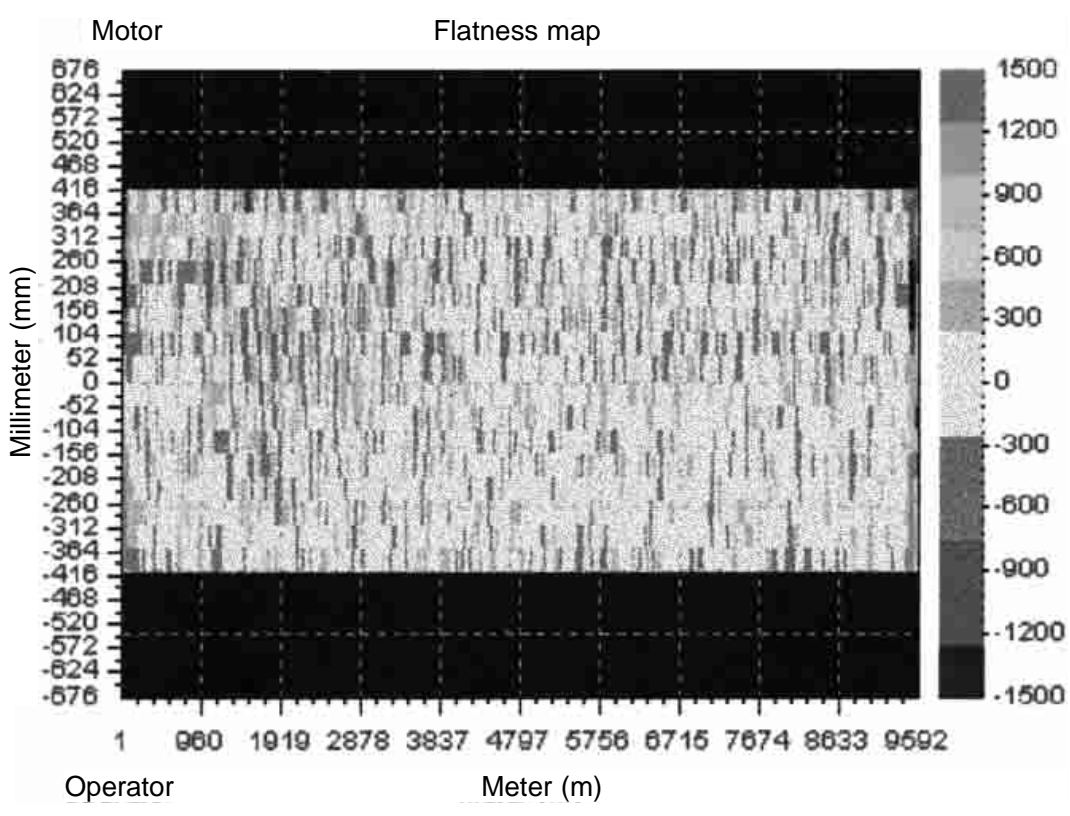

Fig. 5 - Flatness image of coil 585.

Fig. 5 - Carte de planéité de la bobine $n^{\circ} 585$. 


\section{Prediction of cold flatness}

The information fusion, or sensor merger, can be carried out by transforming the flatness map when the strip is hot, in a cold flatness map. In this process the information about the temperature of the material is essential, because it provides the contraction rate of the material at any position. Of course, all this process can be done in real-time, allowing the fast detection of cold flatness defects even before the strip gets cold.

The fault detection process consists of several steps. The first step in this process is the acquisition of the temperature and the flatness. The temperature is acquired from the thermographic sensor through an analogical line, and the flatness is acquired from the process computer through a dedicated Ethernet line. Using all this information combined with the material properties, the cold flatness is estimated. The new flatness estimation is carried out by applying the physics law of thermal contraction to obtain the reduction of the material, and then recalculating the flatness of the strip after this reduction. Finally a fault detector is in charge of determining the flatness problems.

The process to calculate the cold flatness map involves the use of the information provided by the thermographic sensor, by the flatness sensor, and the material properties.

The material properties are used to determine the temperature-contraction ratio, which is often provided as a curve. In this case, a straight line can fit the curve (eq. [4]) :

$$
y=0.14625 x+12.25
$$

where y represents the length variation, measured in millimetres multiplied by $10^{-4}$, and $\mathrm{x}$ represents temperature, measured in degrees centigrade.

Using this equation, the length contraction caused by the temperature drop can be calculated.

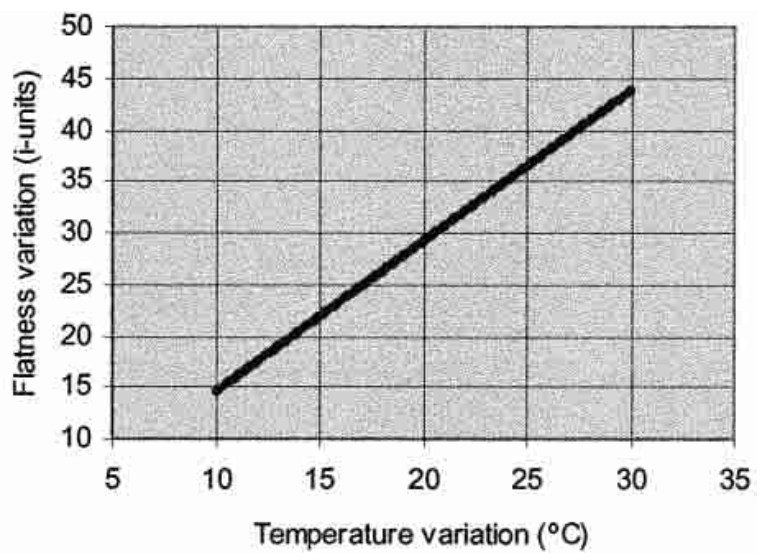

Fig. 6 - Flatness variation measured in i-units caused by the temperature variation.

Fig. 6 - Relation entre la variation de température de la bande et celle de la planéité exprimée en U.I.
Since the outstanding information is not the temperature itself, but the temperature variation $(\Delta \mathrm{T})$, only the slope of this function will be used.

The conversion from $\Delta \mathrm{T}$ (temperature variation), to $\Delta \mathrm{F}$ (flatness variation measured in I-units) is done using the flatness equation :

$$
\Delta F=\frac{\Delta L}{L} \cdot 10^{5}
$$

where $\mathrm{L}$ is the length base $1000 \mathrm{~mm}$, and $\Delta \mathrm{L}$ is obtained directly from equation :

$$
\Delta L=\Delta \mathrm{T} \cdot 0.14625 \cdot 10^{-4} \frac{\mathrm{mm}}{\mathrm{mm}}
$$

Changing units the final equation is :

$$
\Delta L=\Delta \mathrm{T} \cdot 0.14625 \cdot 10^{-1} \frac{\mathrm{mm}}{\mathrm{m}}
$$

Using these equations, the flatness variation in I-units can be direcly calculated from the temperature variation.

Figure 6 shows the graphic representation of the conversion from temperature variation to flatness variation. As can be seen, small temperature variations provoke a high flatness variation.

Using this process, the new flatness map can be calculated from the measured flatness map and the measured thermographic map. In order to simplify the new flatness map calculation, longitudinal fibers are going to be considered independently, which will generate a pessimistic flatness estimation. The number of different fibers considered is determined by the flatness meter resolution, which is 26 .

The first step in the process of getting the new map is to obtain the temperature at every point where the flatness was measured. This step is carried out using the rolled length information obtained from the process computer during the temperature acquisition.

The second step is the calculation of the average temperature in every transverse section. The temperature variation in each fiber of the transverse section is calculated using the average calculated before. Fibers with higher temperature will show a negative variation and fibers with lower temperature will show a positive variation.

The temperature variation $(\Delta \mathrm{T})$ is calculated using the average, and not the lower value of the transverse section. It is done this way to maintain the same scale (negative-positive) since absolute values are not important, but relative values are.

The $\Delta \mathrm{T}$ calculated is used in equation [7] to obtain $\Delta \mathrm{L}$, and then this value is used in equation [5] to obtain $\Delta \mathrm{F}$. Finally, this value is added to the original flatness measured when the strip was being rolled.

The calculated new flatness map of the same strip as in the previous figures, that is, the cold flatness map, is shown in figure 7. 


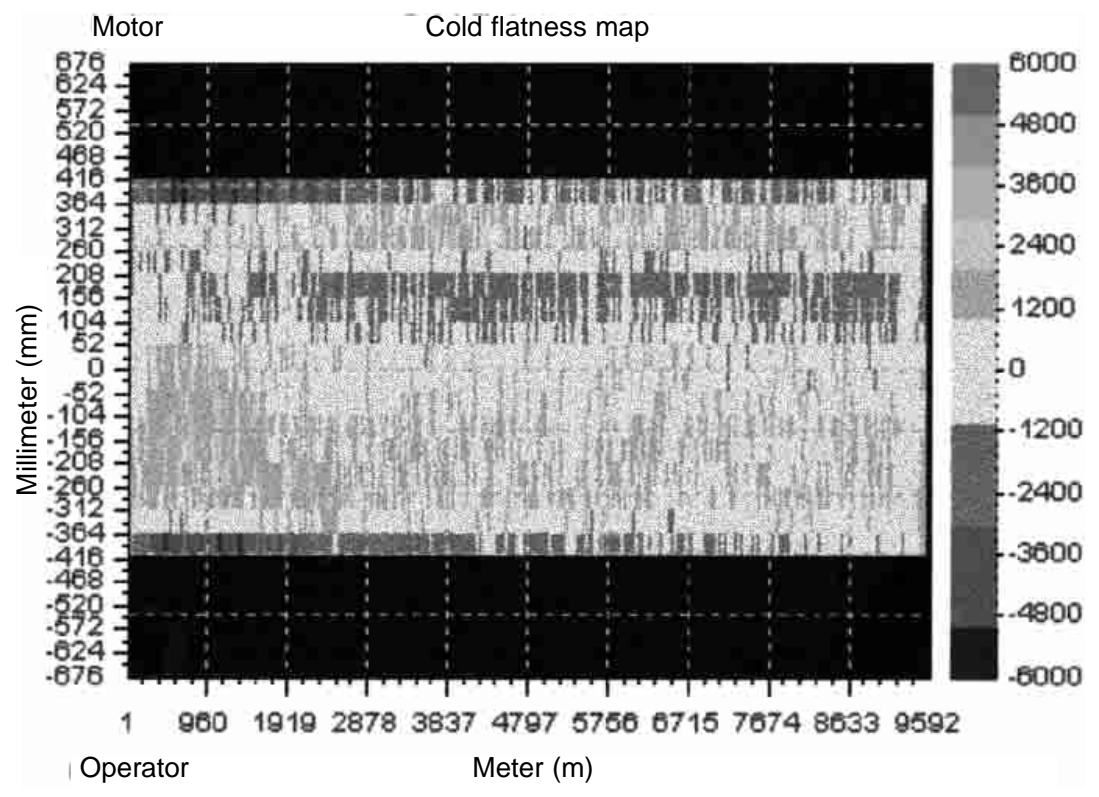

Fig. 7 _ Estimation of the flatness indices of strip 585 after cooling.

Fig. 7 - Estimation des indices de planéité de la bobine $n^{\circ} 585$ après refroidissement.

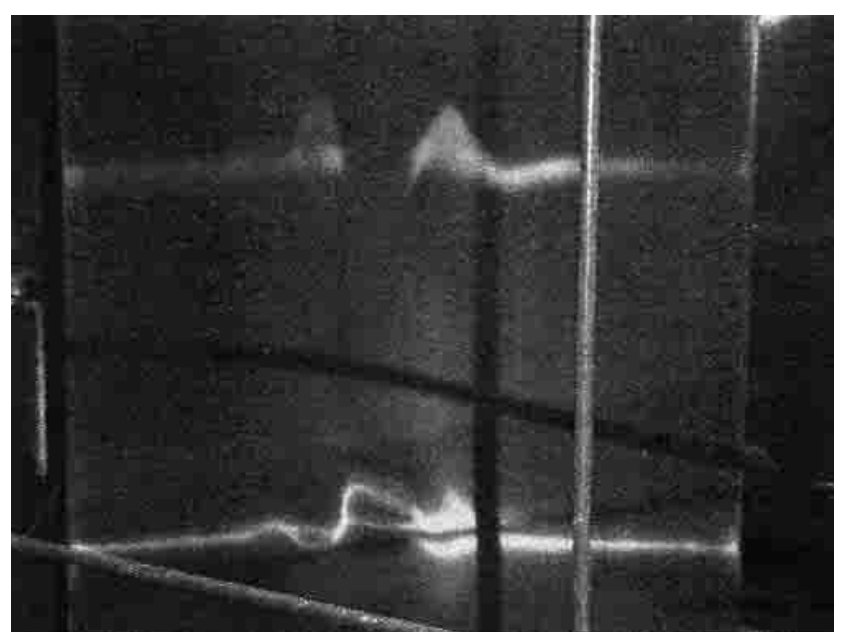

Fig. 8 - Photograph taken under an oblique light.

Fig. 8 - Vue photographique d'une bande sous un éclairage oblique.

As it can be seen, the resulting map is quite different from the flatness map obtained during rolling. In contrast to the old map, two stretched areas appear at the edges of the strip, and a loose area appears in the centre of the strip.

The information provided by the cold flatness map is corroborated by the information provided by the quality control engineers, which means that the high temperature areas in the edges of the strip provoke the strip to be so stretched.

In figure 8, a photograph of the strip is shown. The photograph was taken in the next processing line after the rolling, continuous annealing. The strip is illuminated using an oblique light to make easy the search of defects.
As it can be seen, the light illuminating the strip is very uniform at the edges of the strip. However, in the centre of the strip the light gets distorted. This distortion is due to the fact that the strip is loose in that area.

\section{- CONCLUSIONS}

In this work, temperature gradients have been shown to be at the origin of flatness defects due to thermal contraction effects. This thesis has been demonstrated calculating the cold flatness map, and comparing it with the information provided by the visual inspection of the quality control engineers.

Two main conclusions can be drawn from this work :

- The non-uniformity of temperature across the width of the strips during their rolling generates flatness defects, due to differences in thermal contraction of the different longitudinal fibers that compose a strip.

- The use of the themographic information to transform the flatness map of the hot strip obtained under tension, in a flatness map of the cooled strip without tension is the better way to predict the flatness defects due to nonuniformity of temperature.

\section{REFERENCES}

(1) NEWMAN (T.S.), JAIN (A.K.) - A survey of automated visual inspection. Computer Vision and Image Understanding, 61, No. 2 (199), p. .231-261.

(2) THOMAS (A.D.H.), RODD (M.G.), HOLT (J.D.), NEIL (C.J.) - Real-time industrial visual inspection : a review. Real-Time Imaging, 1, No. 2 (June 1995), p. 139-158.

(3) KAPLAN (H.) - Practical applications of infrared thermal sensing and image equipment. SPIE press. vol. TT34, Tutorial Texts in Optical Engineering (1999).

(4) Land Infrared. LandScan LineScanner Operating Instructions Land Infrared, Publication No. PP970170 (1997).

(5) Land Infrared. LandScan for Windows NT. Land Infrared, Publication No. LS970791 (1998).

(6) National Instruments. PCI E Series User Manual National Instruments, Part No. 320945D-01 (1999).

(7) JONES (L.) - Infrared thermometry for the hot mill. Advanced Steel (1998), p. 186-188.

(8) SALISBURY (R.) - Advances in infrared line scanning for hot strip mill temperature measurement. Steel Times International (September 1997), p. 31-36. 